Revista de Sociología

№ 19 - 2005

Facultad de Ciencias Sociales - Universidad de Chile

(p. 159 - 170)

\title{
EXCLUSIONES EN LA EDUCACIÓN SUPERIOR CHILENA: PREGUNTAS ABIERTAS PARA EL SIGLO XXI
}

\section{Andrés Donoso Romo*}

A mi padre y a todos los que aportan al camino de la educación superior popular.

El presente escrito observa y analiza de manera sistemática la propuesta historiográfica del libro "Intelectuales y Educación Superior en Chile. De la Independencia a la D emocracia Transicional, 1810-2001", compilado por Robert Austin, Editado por CESOC en Santiago de Chile el año 2004. La intención es apreciar sus aportes a la comprensión de la historia chilena de la educación superior, de la educación superior popular y el papel de los intelectuales en ellas. Para lograr esto se analizó la obra, las intervenciones realizadas en su lanzamiento y una entrevista al compilador.

El trabajo consta de tres secciones: la primera refiere a la A rquitectura de la propuesta, que expone los antecedentes históricos del texto y sus creadores, distinguiendo esta historiografía como subalterna y, por tanto, dotada de altas dosis de originalidad. La segunda reflexiona sobre las $\mathrm{E} x$ dusiones en la historia dela educación superior en Chile, presentando las principales tesis, contenidos y ejes estructurantes de la obra, subrayando los persistentes esfuerzos por constituir experiencias de educación superior popular y las conexiones entre educación superior, elites e intelectualidad. Se finaliza con Preguntas desde y para perspectivas críticas en educación superior, que esperan fortalecer las discusiones abiertas y el desarrollo de la educación superior. 
160 Revista De Sociología

№ 19 - 2005

\section{Arquitectura de la propuesta}

El documento se construye gracias a los puentes históricos tendidos entre Australia y Chile protagonizados por Robert Austin, autor-compilador de la obra. Austin, otrora dirigente estu-diantil de la Universidad de Sydney, D octor en Historia de la Universidad de La Trobe, Melbourne-Australia, y actual profesor visitante en la Universidad de Matanzas, Cuba, pone su mirada en el Chile de los 70' para analizar lo que para muchos intelectuales de occidente-donde se incluye- constituirá un escenario particular de asunción pacífica-democrática del socialismo y, posteriormente, de imposición traumática del neoliberalismo.

Austin viaja a Chile en dictadura, vive la represión y la solidaridad producto de la profundidad de la violencia humana. Aquí conoce a su compañera, Viviana Ramírez, quien desde entonces va acompañando su acción y reflexión. D e regreso en Australia formó parte del 'Comité de Solidaridad Australiano con Chile', siendo inclusive editor general de su boletín institucional 'Chile Libre'.

La educación popular fue el pretexto académico-político que lo vinculó inicialmente a estos meridianos. Es la educación superior popular y el papel de los intelectuales, a veintiocho años de conocer Santiago de Chile, lo que sigue cautivando su pensamiento. D esde la década de los $90^{\prime}$ el interés por comprender lo que ocurre en Chile se incrementa a raíz de que gran parte de los países occidentales impulsan estrategias tendientes a consolidar el neoliberalismo, proceso que aquí se consuma durante la dictadura militar. D e esta manera, analizar la educación superior en Chile cobra para Austin relevancia adicional al otorgar puntos de comparación para su localidad.

Las preguntas que dan sentido al texto surgen al alero de jornadas de discusión realizadas en Santiago a mediados de los 90', en las que participaron varios de los autores del libro, siendo Austin su principal gestor. Las preguntas funda-cionales fueron: “ ¿Dónde estaban las historias de la educación superior chilena? [... ] ¿Cómo podría ser [qué] en un país con tanta trayectoria de lucha sobre el acceso a la educación superior no hubiera trabajo que conjugara esa historia?" (Austin, entrevista). Estas preguntas se presentaron en el texto como objetivos: "dar cuenta del proceso dinámico, de avances y retrocesos, reformas y contrarrefor-mas, que han caracterizado a la educación superior chilena en su fase republicana. [Para ello] Los capítulos están escritos desde distintas perspectivas en un afán de generar debate, aclarar y rescatar las particularidades históricas [... ]" (Austin, 2004: X).

El texto se propone observar fenómenos históricos desatendidos por las miradas tradicionales sobre la educación superior y generar-provocar debates a partir de la estimulación de un enfoque teórico crítico de los procesos educacionales 
internos en Chile ${ }^{1}$. Para alcanzar estos propósitos se coordinaron siete investigadores e investigadoras, quienes crearon ocho capítulos en 265 páginas, obteniendo un sugerente relato histórico de la educación superior articulado en las variables de clase social, género y etnia.

La forma y contenidos de libro no dejan indiferente a sus lectores. Su singularidad reside, en parte importante, en la subordinación que afecta a esta mirada, la que hace que su lectura se apoye en gran medida en la voluntad del lector, a diferencia de la historiografía tradicional que goza de una legitimidad dada previamente. El destino del texto es mantenerse cerrado o utilizarse como plataforma para construir comprensiones críticas de la realidad.

Mantener cerrado el libro sería producto de lógicas argumentativas hege-mónicas -por tanto frecuentes- que niegan sistemáticamente la diversidad de puntos de vista por considerar que sus contenidos -protagonistas, instituciones y procesos- no se ajustan a la narrativa histórica tradicional. Las justificaciones para ello serían del tipo: que el autor principal es extranjero y no posee un conocimiento pertinente sobre lo local 0 , que el texto no satisface los cánones estimados como deseables.

Abrir el libro no asegura su examen crítico, ello porque invita al lector a pronunciarse sobre una historia que muchas veces le incomoda por interpelar el trabajo intelectual hegemónico, lugar de enunciación de muchos de nosotros. Lo que genera que, pese a considerarse el libro, se tienda a subvalorarle.

Al evaluar metódicamente los aportes del libro se destaca su capacidad de abrir ventanas de pensamiento, operando como abrelatas reflexivo-cultural. Logrando provocar preguntas al utilizar recursos sugestivos como la estupefacción, la rabia, la vergüenza, entre otras. Su lectura minuciosa alimenta la curiosidad, activa la memoria histórica e insta a pensar sistemáticamente en el pasado, solicitando la emisión de juicios y/ o narraciones originales de la historia.

\section{Exclusiones en la historia de la educación superior en Chile}

La historia de exclusiones de la educación superior en Chile que presenta el texto se expondrá desde tres entradas. La primera tiene que ver con un marco procesual que da cuenta de las constantes que posee la exclusión, presentando comprensiones transversales a la historia de la educación superior en Chile. La

\footnotetext{
1"El libro tiene la distinta intención, de ninguna manera modesta, de intervenir en este debate. Tratar de estimular un nuevo enfoque en los procesos internos de Chile, por ser en particular un país modelo, en sentidos positivos y negativos. País que produjo, antes que la mayoría del mundo, la integración de la mujer a la educación superior, que ha producido tantos avances en el siglo XX. Sigue siendo un faro para muchas partes, no solamente del tercer mundo." (Austin, presentación).
} 
162 Revista De Sociología

№ 19 - 2005

segunda refiere al comportamiento de la educación superior hacia los grupos tradicionalmente excluidos -sectores populares, mujeres y pueblos indígenas-, atendiendo a las particularidades e implicancias de cada vinculación. La tercera se concentra en la contemporaneidad de la educación superior y la intelectualidad, sustentando la comprensión de que no habría una ruptura sustancial entre la dictadura militar y los gobiernos postdictatoriales y que la intelectualidad ha desviado su preocupación desde el compromiso social hacia la condescendencia neoliberal.

\section{Constantes histónicas en la educación superior}

El sistema educacional en la república, no obstante los cambios formales sucedidos una vez consolidada la inde-pendencia, remite sus bases al período colonial. Este postulado se entronca con aquellas interpretaciones que señalan que las luchas independentistas continentales fueron pugnas, entre sectores de las elites, orientadas a asegurar la continuidad de su situación privilegiada y no, como se insiste en la historiografía tradicional, en obediencia a movi-mientos emancipadores motivados por la supuesta necesidad de dar expresión propia a las particularida-des identitarias y/ o culturales de las colonias (Lynch, 2001: 152)2. "La educación superior en Chile precedió a la formación de la república en 1810 -la administración colonial había fundado la Universidad de San Felipe en 1738, precursora de la Universidad deChile en 1842 [... ] Las universidades fueron concebidas como motor reproductivo de las elites. Se articularon con un estado capitalista semi-colonial y patriarcal." (Austin, 2004: x). Las transformaciones que tendrá la educación superior durante su vida republicana se comprenderían mejor en el marco político-económico más amplio. Sería el sistema económico el que arrastraría cambios en las estructuras sociales y configuraciones culturales, siendo éstas últimas las que precipitarían modificaciones en la educación superior hasta permitir, inclusive, la emergencia de la educación superior popular.

El texto abriga la comprensión de que la educación superior tiene uno de sus sentidos primordiales en la satisfacción de las necesidades intelectuales de las elites, otorgándoles los conocimientos y capacidades requeridas para que se desenvuelvan en las actividades propias del control socio-cultural y políticoeconómico. Ello bajo la premisa de que las elites, una vez educadas con las mejores posibilidades y capacidades que procura la sociedad, serían las encargadas de diseminar dichos conocimientos y aptitudes en las clases populares. Andrés Bello, en los comienzos de la era republicana señaló: “La instrucción literaria y científica

${ }^{2} E$ sta visión está presente ya en José Martí, a fines del siglo X IX, quien señala que las independencias latinoamerica-nas lo fueron sólo en los órdenes político-administrativos, dejando pendiente una efectiva descolonización cultural capaz de proyectar órdenes sociales más justos. "El problema de la independencia no era el cambio de formas sino el cambio de espíritu." (Martí, 1891: 115-6). 
es la fuente de donde la instrucción elemental se nutre y vivifica; a la manera que en una sociedad bien organizada la riqueza de la clase más favorecida de la fortuna es el manantial de donde se deriva la subsistencia de las clases trabajadoras, el bienestar del pueblo." (Bello, 1843:102)3. José Enrique Rodó expresa la continuidad de esta idea señalando, a principios del siglo XX, que "La multitud, esa masa anónima, no es nada por sí misma. La multitud será un instrumento de barbarie o de civilización, según carezca o no del coeficiente de una alta dirección moral. Hay una verdad profunda [... ] que exige que cada país sea juzgado según la minoría y no según la mayoría de los habitantes." (Rodó, 1976: 25). Esta idea fuerza predomina en las estrategias educacionales de la historia republicana chilena hasta 1975, fecha en que comienzan las transformaciones económicas neoliberales. Mario Góngora, reflexionando sobre la política de educación superior de la dictadura militar, evidencia en su discurso este cambio de eje:

"hay que acotar que el aporte fiscal a las universidades se ha reducido constantemente, argumentándose que la universidad chilena sirve a 130 mil alumnos, y los grados medio y básico a 3 millones. El argumento es lamentable: en cosas culturales no se cuenta, sino que se pesa. La tradición occidental ha sido siempre la de que la educación irradia desde las universidades, que preparan las elites del país, hacia abajo. La concepción masiva hoy dominante dará un pueblo sin analfabetismo, pero infinitamente menos cultivado que el de 1940 ó 1970." (Góngora, 1988: 2667).

Bello, Rodó y Góngora ponen de manifiesto los vínculos de reciprocidad entre elites y educación superior. Las elites gozan de los beneficios que comporta el acceso a la educación superior y alimentan la bien conocida promesa que refiere a que, una vez satisfechas sus demandas como clases privilegiadas se podrán beneficiar los sectores marginados.

O tra arista de la idea refiere que, al menos desde los inicios de la república, el sistema educacional es dual e invisibiliza dicha situación. Al tiempo que dota de conocimientos y capacidades de control a los representantes de la elite, entrega habilidades técnicas a las clases subordinadas para desempeñarse en los sistemas productivos. Esta dualidad simbólica, derivada del origen socio-económico de los estudiantes, se refleja en instancias o espacios diferenciados ${ }^{4}$ :

\footnotetext{
3 "En ninguna parte ha podido generalizarse la instrucción general que reclaman las clases laboriosas, la gran mayoría del género humano, sino donde han florecido de antemano las ciencias y las letras [... ] Los buenos maestros, los buenos libros, los buenos métodos, la buena dirección de la enseñanza, son necesariamente la obra de una cultura intelectual muy adelantada." (Bello, 1843: 101).

${ }^{4}$ Bernstein arguye que la diferenciación simbólica-estructural que realiza la educación se lleva a cabo por medio de la instalación de códigos socio-lingüísticos disímiles en el estudiantado. De esta manera, mientras a los estudiantes de las clases privilegiadas la educación le otorga un lenguaje con mayor capacidad de abstracción, análisis y comunicabilidad. A los estudiantes de los sectores populares les refuerza un código restringido en cuanto a su capacidadde abstracción y análisis estructural (Bernstein, 1989).
} 
164 Revista De Sociología

№ $19-2005$

"[Al menos desde 1842] existía [en el país] una estructura educativa de camino dual: un sistema estatal de escuelas primarias teóricamente abierto a todos pero diseñado como el límite de la educación pública, más la enseñanza primaria basada en los conventos para los hijos de la clase adinerada; y un sistema de educación media y superior para las élites culminando en el camino por la universidad patriarcal. Este sistema de camino dual -cultural y políticamente católico, económicamente exclusivo- fue la clara expresión del otrora ilusorio estado docente, establecido por la constitución de 1833" (Austin, 2004a: 5-6).

La cita introduce otro eje transversal del libro, la conformación y desarrollo del estado docente en Chile, vindicado en los aparatos legales del siglo X IX y gran parte del siglo XX. El estado docente desde sus inicios está en pugna con agencias privadas interesadas en socializar a la población, siendo una lucha incesante entre los agentes y objetivos pertinentes para controlar el sistema educacional del país. Luis Rubilar señala que esa riña se repite a fines del siglo X IX (Rubilar, 2004: 154) y, con Robert Austin y Francia Araya (2004), es posible ver como en el neoliberalismo, dicha pelea se inclina favor de posiciones privadas, es decir, hacia la libertad de enseñanza. Con el neoliberalismo se abre "la educación superior al libre mercado, generando un proceso de privatización al que tuvieron pleno acceso como propietarios y creadores de estas instituciones-empresas, personas naturales 0 jurídicas, varias vinculadas a las universidades estatales como autoridades designadas por el régimen de Pinochet" (Austin y Araya, 2004: 235).

\section{E ducación superior y grupos excluidos}

La educación popular es concebida por las elites, a finales del siglo XVIII, como destinada a inculcar en los sectores populares preceptos morales y competencias productivas (Villalobos, 1960: 45). Por su parte la educación superior popular aparece sólo con la independencia.

“En 1813 el gobernante José Miguel Carrera inauguró el Instituto de Educación e Industria Popular (luego el Instituto Nacional), diseñado para promover el estudio de 'las ciencias, artes y oficios, instrucción militar [... ] su clientela fue constitutita sólo por capitalinos privilegiados, quienes sin costo pudieron estudiar en sus tres niveles, desde enseñanza primaria hasta universitaria." (Austin, 2004a: 7).

Las escuelas normales de preceptores, fundadas en 1842 por Domingo Faustino Sarmiento, hacen que la educación superior popular gane en relevancia pública. Ellas serían durante largo tiempo las principales formadores de docentes primarios. Serían el Instituto Pedagógico (1889), la Universidad Popular Ferroviaria 
(1922), Universidad Popular Valentín Letelier (1945) y la Universidad Técnica del Estado (1952) algunas de las instituciones que se sumarían y representarían simbólicamente esta tradición, la que hoy se mantendría en un conjunto de universidades privadas sin fines de lucro, nacidas en la década de los 70' y 80' como proyectos de resistencia a la dictadura y el neoliberalismo ${ }^{5}$. A pesar de su denominación, la educación superior popular se ha observado en la historia de Chile como aspiración de los sectores subordinados pero como proyecto de elites. Tras una larga historia de intentos y recomienzos, la educación superior popular actualmente es vista como horizonte antes que como realidad ${ }^{6}$.

Las mujeres hacen su ingreso a la educación superior en 1852 con la creación de las escuelas normales de preceptoras. Iniciándose así una lucha, aún inconclusa, por la superación de la discriminación educacional. Austin y Vidal estimulan la reflexión con sentencias como: "De ahí que siga vigente el estereotipo según el cual las profesiones 'más propias' de mujeres son aquellas que, de alguna manera, reproducen los roles que ellas desempeñan en el hogar, a saber: cuidar, criar y educar a los hijos. Es decir: ¡varones a la producción y damas a la reproducción!” (Austin y Vidal, 2004: 85).

Enmarcado en distintas perspectivas de género, el texto aborda reiteradamente la discriminación que afecta a las mujeres en la educación superior. Ella se constataría en su marginación de las carreras mejor evaluadas por las elites y en el funcionamiento de una pedagogía oculta que les violentaría, sobre todo en consideración a los objetivos, maneras y contenidos del sistema educacional en general y superior en particular. Torna posible identificar, además, los aspectos legales, institucionales y procesuales que han acompañado la incorporación de la mujer a la educación superior. O torgando un lugar destacado la visibilización de los nexos entre educación superior, dirigentes y desarrollo del movimiento feminista, indicando que las mujeres con educación superior han contribuido enormemente a la dirección de las organizaciones feministas (Salas, 2004: 57)7.

La triada de análisis sobre las exclusiones que genera la educación superior a lo largo de la historia republicana se completa observando la relación conflictiva entre ésta y los pueblos indígenas. Álvaro Bello, intelectual mapuche, sostiene que el sistema educacional margina constantemente a la población indígena y, cuando

\footnotetext{
5 "Por otra parte, la consolidación de las universidades Academia de Humanismo Cristiano, Bolivariana y ARCIS, con diferenciados vínculos al movimiento popular chileno, ha mantenido una simbólica extensión del concepto de la universidad popular, concepto derivado de movimientos obreros y feministas chilenos con orígenes en el siglo XIX..." (Austin y Araya, 2004: 256).

${ }^{6}$ Austin señala, no obstante que la educación superior popular sería una realidad contemporánea en Cuba y Venezuela, entre otros (entrevista).

${ }^{7}$ El texto distingue movimientos feministas con expectativas y vínculos diferenciados con la educación superior, siendo el Movimiento de Mujeres Populares MOMUPO, creado en la década de 1980, una de sus expresiones más originales (Austin y Vidal, 2004: 79).
} 
166 Revista De Sociología

№ $19-2005$

no, les incluye dentro de códigos y normas de una chilenidad que no los reconoce. La educación superior se erigiría como un espacio deseado pero estrecho para el desarrollo de la intelectualidad mapuche, verificándose que sólo a principios del siglo XX algunos varones mapuche ingresan a la educación superior vía escuelas normales, no sin antes enfrentar la violencia simbólica que aqueja a los 'distintos' y/ o vencidos ${ }^{8}$. Al igual que en el caso de la incorporación de la mujeres, estos intelectuales indígenas con formación superior gravitan en el desarrollo de sus organizaciones.

Con el correr del siglo XX la matrícula indígena de la educación superior se incrementa significativamente, siendo el período postdictatorial el que tendrá el crecimiento más significativo, ello gracias a la nueva legalidad, institucionalidad y los recursos públicos concomitantes ${ }^{9}$. Esta mayor presencia se habría dado, entre otros factores, por las demandas educacionales de las organizaciones indígenas. Al respecto se precisa que, "Aunque la demanda por educación estuvo desde un primer momento en el discurso de las organizaciones mapuches, no va a ser sino hasta fines de la década del 50 que el tema de la universidad surgirá en el programa de demandas del sector. Sin embargo, esta demanda estará vinculada en un primer momento a la obtención de becas y hogares y de forma larvaria a la necesidad de formación de recursos humanos." (Bello, 2004: 115).

\section{E ducación superior e intelectualidad en el Chile contemporáneo}

El texto concluye en un análisis sobre la situación actual de los intelectuales y la educación superior en Chile, la que se enmarca en estos términos. En el país existiría una continuidad político-económica desde la dictadura militar, siendo ella la bisagra histórica que introduce el neoliberalismo. Por ello, en estricto rigor, la transición no estaría dándose una vez que asumen los gobiernos de la Concertación, sino que se habría dado en la dictadura militar ${ }^{10}$. Una de las metáforas que mejor expresan esta continuidad sería: "los voceros del gobierno de la Concertación, ya

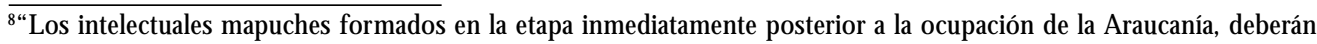
pagar el precio de los vencidos, bajo el peso de una nueva violencia, que no será la de las armas de guerra, sino aquella que provendrá de la violencia simbólica por la imposición de una lengua y cultura ajena." (Bello, 2004: 112). D omingo Faustino Sarmiento, influyente pensador educacional del siglo XIX representa el espíritu de dicha época, tratando a los indígenas como bárbaros: "porque el saber es riqueza, y un pueblo que vegeta en la ignorancia es pobre y bárbaro, como lo son los de la costa de África, o los salvajes de nuestra pampas." (Sarmiento, 1845: 239).

${ }^{9}$ La Ley Indígena no 19.253, promulgada en 1993, prescribió la formación de la Corporación Nacional de D esarr ollo Indígena y, dentro de ella, el Área de Educación y Cultura. También determinó la creación, dentro del Ministerio de Educación, del Programa de Educación Intercultural Bilingüe.

10"discutíamos mucho, con los compañeros y compañeras de Chile allá [en Australia] y otros intelectuales, la visión que ya está incluida en el libro, de que ¿Cuál era este proceso de transición? sino la propia dictadura [afirmación]. O sea se habla mucho todavía de la transición democrática, Alfredo Jocelyn-Holt ha pillado como veintidós significados de la palabra transición. Yo desde un período de hace varios años, de quince o dieciséis años, yo me acerqué al tema de una manera especial. No he visto en ningún momento una ruptura." (Austin, entrevista).
} 
presidida por una nueva generación de la dinastía Frei, celebraban el perfil del 'tigre económico' que en efecto extendía [extiende] en forma secular el 'milagro económico' de la junta militar." (Austin, 2004: IX).

En el contexto neoliberal el estado docente transita hacia el estado ausente. Austin y Araya se avocan a la tarea de reflexionar sobre ello. D urante la dictaduratransición y en el marco del nuevo 'estado subsidiario', no solamente se habría quitado el carácter de gratuidad que tenía la educación superior hasta comienzos de la década de 1970, sino que se cercenó sistemáticamente el pensamiento crítico procurado por las humanidades y ciencias sociales locales bajo la D octrina de la Seguridad Nacional. Esta última significó la supresión de carreras, administrativos, intelectuales y estudiantes no alineados y la descentralización-fragmentación de las universidades estatales nacionales como la Universidad de Chile y la Universidad Técnica del Estado (Austin y Araya, 2004: 236). La educación superior giró bruscamente hacia la gestión e intereses privados, siendo "La rentabilidad - vestida en los códigos del discurso neoliberal, incluso la 'viavilidad del mercado libre' y la 'libre voluntad del inversionista' para crear ganancias- [... ] el criterio fundamental para la existencia de un sector mayoritario de la educación superior privada." (Austin, 2004b: 225) ${ }^{11}$. Los gobiernos de la Concertación no habrían más que mantenido dicha situación, amparándose en una suerte de 'política de la no política' que abandona la problemática y, cuando no, las entrampa en procedimientos burocráticos que operan como escollos para las iniciativas innovadoras (Austin y Araya, 2004: 248).

Por último, la intelectualidad que presenta y promueve el texto es aquella que brega que no se conforma ante las prescripciones del neoliberalismo y, en palabras de Alfonso Sastre, es disfuncional al mismo ${ }^{12}$. Ella ha de situar históricamente sus reflexiones, des-cubrir la pretensión de incidir en el presente y considerar las posturas que le desafían o incomodan, esto último en el entendido que ello fortalece sus análisis ${ }^{13}$.

\footnotetext{
${ }^{11} \mathrm{G}$ arcía de la Huerta señala que "El repliegue del Estado ha significado la anulación del principal agente educador, socializador, modernizador y democratizador. Lo que se ofrece como alternativa en el espacio privatizado de la educación, es una profesionalización radical de la enseñanza superior, con la consiguiente tecnización en las fases intermedias, unido a una reconfesionalización impulsada y encabezada por el O pus D ei." (García de la Huerta, 2004: 163).

${ }^{12}$ Alfonso Sastre, quien forma parte del nosotrosdesde el cual reflexiona Robert Austin, distingue siete premisas de la intelectualidad funcional al neoliberalismo, estas serían: (a) el buen intelectual es -y si no debería serlo- políticamente correcto. (b) El buen intelectual está en contra de toda violencia, venga de donde venga. (c) El buen intelectual es tolerante. (d) El buen intelectual es ciudadano del mundo. (e) El buen intelectual es pacifista. (f) El buen intelectual es demócrata. (g) El buen intelectual, puesto a elegir, prefiere la injusticia al desorden (Sastre, 2005: 91 y ss.)

${ }^{13}$ Estas nociones se conjugan también en la responsabilidad social que poseerían los intelectuales, el "contribuir con ideas desafiantes, con hipótesis, con teorías que no se adapten a las realidades sino que produzcan una permanente incomodidad intelectual y política" (Austin, presentación).
} 
168 Revista de Sociología

№ 19 - 2005

\section{Preguntas desde y para perspectivas críticas en educación superior}

El texto entrega una perspectiva histórica de la educación superior en Chile, que enfatiza las exclusiones que ella procura a los sectores populares, mujeres y pueblos indígenas y que permite apreciar al presente como producto y reactualización del pasado y, al futuro, como un desafío a emprender de la mano de los avances y aprendizajes obtenidos en la lucha de estos sectores por contrarrestar esta situación.

La alusión a la educación superior popular desencadena en un primer momento la pregunta ¿Existen experiencias concretas en educación superior popular en Chile?. Historiografías subalternas como la expuesta dan respuestas afirmativas y otorgan profundidad a problemáticas contemporáneas como, por ejemplo, la pugna entre partidarios del estado ausente (gobierno, empresariado y derecha política) y del estado docente (colegio de profesores, organizaciones estudiantiles y culturales). Problemáticas como éstas, de no contar con visiones de larga duración, se apreciarían como contingentes, pasajeras y/ o sin importancia. La postura aquí bosquejada insiste en que no se debe normalizar el contradictorio escenario educacional producido por el neoliberalismo y advierte los perversos vínculos existentes entre elites, intelectualidad y educación superior.

Los discursos legitimados para analizar, enjuiciar y controlar la educación superior provienen de intelectuales con abundantes estudios superiores y que pertenecen a las elites. La intelectualidad tiende a invisivilizar algunas problemáticas, discusiones y constantes históricas relativas a la estructura, eficacia y eficiencia de ésta educación y a privilegiar problemas gremiales como la necesidad de aumentar los recursos económicos para esta actividad. D etrás de este discurso se encuentran mitos como la 'meritocrácia' y/ o el que los beneficios de la educación superior se extenderán a los sectores postergados una vez que exista una elite cultivada capaz de rebalsar sus conocimientos sobre los demás sectores sociales. Con Paulo Freire (1972), se concibe que la pretensión de extender conocimientos desde quien sabe a quien no, es un mecanismo de mantención de la estructura social y no una estrategia de propagación de los beneficios de la educación superior. La educación popular y la educación superior popular tienen un camino recorrido en Chile y el continente, el no olvidar los aprendizajes obtenidos es uno de los principales derechos y obligaciones de la intelectualidad que no se limita a consentir al neoliberalismo.

Para concluir se elaboran preguntas que interpelen a los creadores del texto $\mathrm{y}$ al nosotros del cual forman parte. Cuestionamientos que buscan repensar y pro-fundizar esta perspectiva comprensiva, en vistas de aportar a un diálogo con su historia y, muy espe-cialmente, con el presente y los futuros posibles.

¿Pueden los intelectuales, como representantes de las elites y beneficiarios directos de la educación superior, aportar a una reorientación estructural significativa 
de la educación superior? ¿Qué responsabilidad tienen y han tenido los sectores históricamente excluidos de la educación superior en esta marginación? ¿Q ué papel desempeña la introyección de la dominación cultural en los sectores excluidos?

¿Qué los sectores populares gocen de la educación superior es un fin en sí mismo o responde a una estrategia de construcción de una realidad distinta signada por la justicia social, económica y cultural? ¿La lucha por el acceso de los sectores marginados a la educación superior es compatible con la exigencia de mejoras en la calidad y pertinencia de la misma?

Al finalizar sólo resta subrayar que el texto cumple con el objetivo político de activar la memoria histórica e impulsar debates sobre las problemáticas tratadas. Mis más sinceros agradecimientos a Robert Austin por las facilidades otorgadas en el desarrollo de este trabajo y por entregarnos visiones que promueven la reflexión interna.

\section{Referenciasbibliográficas}

Austin, Robert (entrevista) entrevista personal, 19 de julio de 2005, Santiago de Chile.

Austin, Robert (presentación) intervenciones en lanzamiento del libro Intelectuales y Educación Superior en Chile, D e la Independencia a la D emocracia Transicional, 1810-2001. Compilado por Robert Austin, Editado por CESOC, Santiago de Chile 2004. Realizado en Instituto Chile, 16 Junio de 2005, Santiago.

Austin, Robert (2004) “Introducción”. En: Austin, Robert [comp.] (2004) Intelectuales y Educa-ción Superior en Chile, De la Independencia a la D emocracia Transicional, 1810-2001, Ediciones CESO C, Santiago de Chile, pp. IX-XVII.

Austin, Robert (2004a) “Estado, Pobladores y Educación Superior, 1842-1952”. En: Austin, Ro-bert [comp.] (2004) Intelectuales y Educación Superior en Chile, D e la Independencia a la D emocracia Transicional, 1810-2001, Ediciones CESO C, Santiago de Chile, pp. 1-38.

Austin, Robert (2004b) "Fuerzas Armadas, Fuerzas del Mercado: Intelectuales y Educación Su-perior, 1973-1990". En: Austin, Robert [comp.] (2004) Intelectuales y Educación Superior en Chile, D e la Independencia a la D emocracia Transicional, 1810-2001, Ediciones CE SO C, Santiago de Chile, pp. 189-228.

Austin, Robert y Araya, Francia (2004) “¿Dictadura Imaginaria? De transición D emocrática a Renovación Concertacionista en la Educación SuperiorChilena, 1990-2001. En: Austin, Robert [comp.] (2004) Intelectuales y Educación Superior en Chile, De la Independen-cia a la D emocracia Transicional, 1810-2001, Ediciones CE SO C, Santiago de Chile, pp. 189- 228. 


\section{$170 \mid$ Revista De Sociología}

№ $19-2005$

Austin, Robert y Vidal, Paulina (2004) “Género, Intelectuales y Educación Superior en Chile”. En: Austin, Robert [comp.] (2004) Intelectuales y Educación Superior en Chile, D e la Independencia a la Democracia Transicional, 1810-2001, Ediciones CESO C, Santiago de Chile, pp. 59-98

Bello, Álvaro (2004) "Intelectuales Indígenas y Universidad en Chile: Conocimiento, D iferencia y Poder entre los Mapuches". En: Austin, Robert [comp.] (2004) Intelectuales y Educación Superior en Chile, De la Independencia a la Democracia Transicional, 1810-2001, Edi-ciones CESO C, Santiago de Chile, pp. 97-132

Bello, Andrés (1843) "D iscurso Pronunciado en la Instalación de la Universidad de Chile, el 17 de Septiembre de 1843". En: G rases, Pedro (1970) Antología de Andrés Bello, Editorial Kapelusz, Caracas, pp. 95-109.

Bernstein, Basil (1989) Clases, Códigos y Control. Editorial Akal, Madrid

Freire, Paulo (1972) ¿Extensión o Comunicación?, ICIRA, Santiago de Chile.

García de la Huerta, Marcos (2004) Pensar la Política, Editorial Sudamericana, Santiago de Chile.

Góngora, Mario (1988) Ensayo Histórico sobre la Noción de estado en Chile en los Siglos XIX y XX, Editorial Universitaria, Santiago de Chile.

Lynch, John (2001) “Las Raíces Coloniales de la Independencia Latinoamericana”. En:John Lynch, América latina, entre Colonia y Nación, Editorial Crítica, Barcelona, pp. 117-169

Martí, José (1891) "Nuestra América”. En: Fernández, Roberto [ed.] (1973) José Martí: Cuba, Nuestra América, Los Estados Unidos, Editorial Siglo XXI, México D.F., pp. 111-120.

Rodó, José Enrique (1976) Ariel, a la Juventud de América, Biblioteca Ayacucho, Cararcas.

Rubilar, Luis (2004) "El Movimiento Estudiantil Chileno y la Reforma Universitaria: 1967-1973”. En: Austin, Robert [comp.] (2004) Intelectuales y Educación Superior en Chile, D e la Independencia a la D emocracia Transicional, 1810-2001, Ediciones CESO C, Santiago de Chile, pp.133-150.

Salas, Emma (2004) "La Educación Superior y los Movimientos de Emancipación de la Mujer Chilena, 1877-1950". En: Austin, Robert [comp.] (2004) Intelectuales y Educación Supe-rior en Chile, D e la Independencia a la D emocracia Transicional, 1810-2001, Ediciones CE SO C, Santiago de Chile, pp. 39-58.

Sarmiento, D omingo Faustino (1845) "Presente y Porvenir". En: Sarmiento, D omingo Faustino (1977) Facundo, Editorial Biblioteca Ayacucho, Caracas, Venezuela, pp.225-244.

Sastre, Alfonso (2005) La Batalla de los Intelectuales 0 Nuevo discurso de las Armas y las Letras, CLACSO, Buenos Aires.

Villalobos, Sergio (1960) “El Bajo Pueblo en el Pensamiento de los Precursores de 1810”. En: Anales de la Universidad de Chile, no 120, Cuarto Trimestre de 1960, Santiago de Chile, pp. 36-49. 